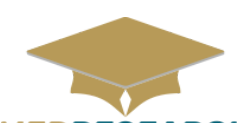

MEDRESEARCH

www.medresearch.in

\title{
Study on quality assessment of child health care services in a district of Assam
}

P Rabha A. ${ }^{\text {* }}$

DOI: https://doi.org/10.17511/ijphr.2017.i5.03

1* Alpana P Rabha, Assistant Professor, Department of Community Medicine, Assam Medical College, Dibrugarh, Assam, India.

Introduction: Children less than five years of age is a critical indicator of the wellbeing of children. In order to reduce infant as well as under-five mortality rate of children, Govt of India has initiated different health programmes as well as recommended Indian Public Health Standards for health care facilities to provide quality health care. Objective: To assess the quality of child health care services at health care facilities at primary and secondary level. Methodology: A cross-sectional study had been conducted at CHCs, PHCs and S/Cs in Kamrup district of Assam. The data had been collected by quality assessment checklists and exit interview with the clients availing the child health services at the health care facilities. Results: The quality of child health care services was assessed by using a system approach-inputs, process and outputs. There were only $66.66 \%$ availability of Obstetrics \& gynaecology specialist and paediatrician. Physician were available in $33.33 \%$ of CHCs. The availability of trained personals was found to be inadequate in all the CHCs and PHCs. Most of the equipments and supplies were available in all the health care facilities. The child health care activities in areas of immunization and cold chain maintenance was found to be satisfactory. Conclusion: The quality of child health care services was found to be average at primary and secondary level.

Keywords: Child health, Quality of Care, Infant Mortality Rate, Quality

Corresponding Author

Alpana P Rabha, Assistant Professor, Department of Community Medicine, Assam Medical College, Dibrugarh, Assam, India.

Email: alporabha@gmail.com
How to Cite this Article

Rabha AP. Study on quality assessment of child health care services in a district of Assam. Public Health Rev Int J Public Health Res. 2017;4(5):117124.

Available From

https://publichealth.medresearch.in/index.php/ijphr/ article/view/71
To Browse

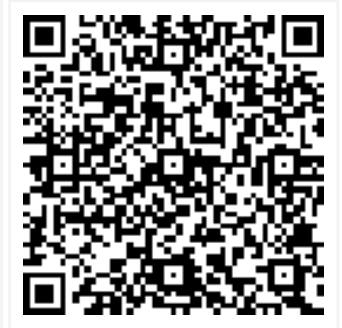

Manuscript Received 2017-11-18

Conflict of Interest No

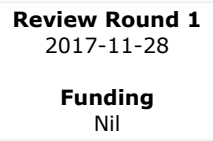

Review Round 1 Nil

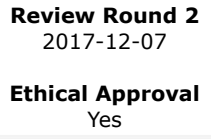

Review Round 3

Plagiarism X-checker $8 \%$
Accepted 2017-12-12

Note

(c) 2017 by Alpana P Rabha and Published by Siddharth Health Research and Social Welfare Society. This is an Open Access article licensed under a Creative Commons Attribution 4.0 International License https://creativecommons.org/licenses/by/4.0/ unported [CC BY 4.0]. 


\section{Introduction}

Each year 27 million children are born to India. Around ten percent of them do not survive to 5 years of age. India contributes to 25 percent of the over 6.9 million under-five deaths occurring worldwide every year. The quality of human resources of any country is largely determined by the quality of the child development services [1]. India is still lagging behind ideal health conditions as seen from infant mortality rate and under five mortality rate of $47 / 1000$ (2010) and 59/1000 live birth (SRS-2010) [2].

India has tried to cope up with these problems by formulating various national health programmes and strategies for prevention and control of under five mortality rates. The quality of care was emphasized at the International meeting organized by WHO in Almaty in 1998 to celebrate 20 years of the AlmaAta Declaration [3]. Responsiveness, which is one of the three intrinsic goals of a Health system, could also be regarded as a measure of the quality of care.

Health care quality assessment and improvement has become a growing issue in health care system of all countries. Quality influences both health status and satisfaction. The quality of care generally means the degree of excellence of the medical care delivered. Quality is achieved when accessible services are provided in an efficient, cost-effective and acceptable manner. Quality is achieved when the needs and expectations of the customer are met [4].

Patient's satisfaction is an important part of health care. It is also a measure of quality of care. Avedis Donabedian (1966; 1980) [5] described quality as including: structure (viewed as the capacity to provide high quality care), process (often termed as performance) and outcome.

As studies on child health care quality was not done previously in this region, the present study had been proposed to be carried out in Kamrup district of Assam to assess the quality of child health care services at primary and secondary level and to identify the weakness so that the appropriate measures might be taken to provide responsive and effective care to every child.

\section{Methodology}

Study Design: Cross-sectional study
Study Area \& Sampling procedure: The study had been undertaken in Kamrup District of Assam covering various health institutions from $\mathrm{CHCs}$, PHCs and Sub-centre during one-year period. From total numbers of nine CHCs \& twelve PHCs, 30 percent of $\mathrm{CHCs}$ and 40 percent of PHCs had been selected randomly for the study. From each PHCs, two sub centres had been selected randomly based on their distance from the $\mathrm{PHC}$, one within five kilometres and the other situated more than five kilometres from the selected PHCs.

\section{Study Instruments}

01. Quality Assessment Checklists for $\mathrm{CHC} / \mathrm{PHC}$.

02. Quality Assessment Checklists for Sub-centres.

03. Exit Interview with the clients availing the child health care services.

Study Population: The study population comprised of:

01. Health care provider (MO, ANM/LHVs) and laboratory technicians.

02. Health care seekers (mothers of children of 0 5yrs of age availing the child health care services.

03. Records.

\section{Study variables}

01. Staffing pattern/Manpower.

02. Availability of equipments and supplies.

03. Child health care quality.

04. Providers' availability.

Data Collection Method: The data had been collected by periodical visits to the selected health care facilities ( $\mathrm{CHC}$, PHC \& S/cs). The information was collected from those facilities by the following procedures-

01. Inputs from records.

02. Interviews of the health personnel (MO, ANM/LHV, Lab technician etc).

03. Observation method.

Assessment of Quality Services- The quality of the health care facilities were assessed following the conceptual framework proposed by Donabedians (1980) three major aspects of quality of care [5]-

01. Service inputs

02. Service process

03. Service output. 
Service Input- The service input comprised of infrastructures, drugs \& supplies, provider's availability( skilled/ trained), and availability of protocols/ guideline.

Service Process- It includes the technical quality of service counselling (providing the clients with important information in an acceptable way) and procedure of delivery of services. It was assessed by an observational proforma (Checklists for $\mathrm{CHC}$ / PHC \& S/C).

Service Output- It includes the clients satisfaction level availing the child health care services at the Community health centres and Primary health centres. The interview schedule was prepared from Operational Manual of Quality Assurance for District Reproductive and Child health services in Public health system.

In the present study, for client satisfaction had been assessed by exit interview on the basis of 12 point scale \& scoring system for positive responses. Based on the number of positive responses, services were categorized as 'very good' 10-12points graded as $A$; 'good' 7-9points as B; 'average'4-6points graded as $C$; and 'poor' 1-2points graded as D.

The data had been collected by exit interview in the OPDs using pretested \& predesigned structured schedule. The child health services include ARI, diarrhoea, immunization and others. Three clients were interviewed for each service area in each of the facility. Thus, a total 96 clients were interviewed for client satisfaction.

\begin{tabular}{|l|l|l|}
\hline \multicolumn{1}{|c|}{ Category } & \multicolumn{1}{c|}{ Grade } & \multicolumn{1}{c|}{ Score } \\
\hline Very good & A & $10-12$ \\
\hline Good & B & $7-9$ \\
\hline Average & C & $4-6$ \\
\hline Poor & D & $1-3$ \\
\hline
\end{tabular}

Statistical Analysis: The statistical analysis was carried out by using percentages.

\section{Results}

The role of health manpower in determining the quality of health care is now increasingly appreciated. There were only $66.66 \%$ availability of Obstetrics \& gynaecology specialist and paediatrician. Physician were available in $33.33 \%$ of $\mathrm{CHCs}$. None of the $\mathrm{CHCs}$ had the available surgeon in position. Anaesthetist were available in 2 of 3 CHCs. The MOs were available in all the CHCs. Other supporting manpower including staff nurses, pharmacists/ compounder, lab.
Technicians were available in all the CHCs. In most of the PHCs, the MOs were available. The Ayush/ Homeo doctors were available only in $60 \%$ of the PHCs. The other supporting staffs were also available in all the PHCs (Table No1).

In the present study, all the $\mathrm{S} / \mathrm{Cs}$ had the available health worker (F)/ANM. None of the S/Cs had the available health worker (M) (Table No2).

All the health care facilities had proper arrangement for the segregation of wastes generated at the facilities. This was probably due to implementation of Infection Management \& Environment Plan (INEP) for Reproductive and child health programme (Phase-II).under Govt. of India, Deptt. of Family Welfare, MOHFW, 2004.(Table No3).

Table No4 shows the distribution of $\mathrm{CHCs}$ and PHCs according to the availability of essential amenities for the clients' comfort. When patients experience high-quality health care and their health improves, they generally feel more satisfied. Scientific evidence indicates the reverse is also true; increased client satisfaction can lead to better health outcomes.

The table shows that all the CHCs and PHCs had the waiting areas for the clients in covered/ shaded areas. The drinking water facilities were also available in all the health care facilities. Toilet facilities for women were available ai all the $\mathrm{CHCs}$ and $60 \%$ of PHCs. A separate labour / delivery room with curtains in windows and doors were available in all the CHCs and PHCs.

Table No 5 shows availability of infection prevention supplies at $\mathrm{CHCs}$ and PHCs. All the health care facilities had available infection prevention supplies.

Table No 6 shows the immunization service delivery at $\mathrm{CHCs}, \mathrm{PHCs} \& \mathrm{~S} / \mathrm{Cs}$. In the present study, the child health care quality had been assessed only by observing immunization service delivery which included activities on immunization service, vaccination supplies and cold chain management.

It had been observed that all the CHCs, PHCs\& S/Cs had well maintained the immunization service delivery. The post immunization advice regarding side effects and follow-up were observed in only $66.66 \%$ of $\mathrm{CHCs}$ and $60 \%$ of PHCs. The vaccines logistics and supplies were available in all the health care facilities. The cold chain were also well maintained in all the health care facilities. 
The advice on immunization and follow-up visits as well as updated/ completed immunization card was also found to be $100 \%$ at all the S/Cs. The drop out rates were also traces by the ANM. Anganwadi workers and ASHA also were found to be participated during the immunization sessions at all the Sub-centres.

Table No 7 shows the distribution of $\mathrm{CHC}$ and $\mathrm{PHC}$ according to the availability of equipment and supplies. From the table, it had been observed that the availability of BP apparatus with stethoscope and weighing machine (adult/ infant) were available to all the CHCs and PHCs. The autoclave/ boiler were available in $66.66 \%$ of $\mathrm{CHCs}$ and $60 \%$ of PHCs.

The complete delivery kits were available in all the $\mathrm{CHCs}$ and PHCs. The sterile MVA syringes were available in $66.66 \%$ of CHCs and none of the health care facilities had the available EVA. The paediatric resuscitation kits were available in all the $\mathrm{CHCs}$ and PHCs.

Table No 8 shows the distribution of clients satisfaction on child health care services at Primary health care centres. The shows that the satisfaction level of clients on child health i.e on ARI 03as 'very good' and 08 as 'good'; on diarrhoea 'very good' 01,'good'12; and 'average' 07; on immunization 'very good'06, as good'12, as 'poor'02; on others 'very good'05, as 'good'04.

So, out of 60 clients 11 had' very good 'level of satisfaction, 36 had 'good', 07 had 'average' and 02 had 'poor' level of satisfaction on child health care services at Primary health care centres.

\section{Table No-1: Distribution of Manpower at the} CHCs and PHCs.

\begin{tabular}{|l|l|l|}
\hline \multicolumn{1}{|c|}{ Manpower or Staff } & No of $\mathbf{C H C ~ N = 3}$ & No of PHC No $=\mathbf{5}(\%)$ \\
\hline Specialists-obs/gynae. & 2 & - \\
\hline Paediatrician & 2 & - \\
\hline Physician & 1 & - \\
\hline Surgeon & 0 & - \\
\hline MOs---MBBS & 3 & 5 \\
\hline Staff nurse-GNM/PHN & 3 & 5 \\
\hline Pharmacists/Compounder & 3 & 5 \\
\hline Laboratory technician & 3 & 5 \\
\hline
\end{tabular}

Table No-2: Distribution of Manpower at the Sub-centre

\begin{tabular}{|c|c|c|}
\hline $\begin{array}{c}\text { Name of } \\
\text { staff/manpower }\end{array}$ & $\begin{array}{c}\text { No of Sub- } \\
\text { centre( } \mathbf{n = 1 0})\end{array}$ & $\begin{array}{c}\text { Availability of } \\
\text { manpower }\end{array}$ \\
\hline ANM/Health worker(F) & 10 & 10 \\
\hline
\end{tabular}

Health worker(M)

\begin{tabular}{l|l}
0 & 0
\end{tabular}

Table No 3: CHC and PHC according to the Cleanliness

\begin{tabular}{|l|l|l|}
\hline \multicolumn{1}{|c|}{ Cleanliness of the facility } & $\begin{array}{l}\mathrm{CHC}(\mathrm{n}=3) \\
\text { No }(\%)\end{array}$ & $\begin{array}{l}\text { PHC (n=5) } \\
\text { No (\%) }\end{array}$ \\
\hline General cleanliness & 3 & 3 \\
\hline $\begin{array}{l}\text { Proper arrangements for segregation of } \\
\text { wastes generated at the facility }\end{array}$ & 3 & 5 \\
\hline
\end{tabular}

Table No-4: Distribution of $\mathrm{CHC}$ and PHC according to the availability of Essential Amenities for the clients

\begin{tabular}{|l|l|l|}
\hline \multicolumn{1}{|c|}{$\begin{array}{c}\text { Availability of essential amenities for the } \\
\text { clients comfort }\end{array}$} & $\begin{array}{c}\mathrm{CHC}(\mathrm{n}=\mathbf{3}) \\
\text { No (\%) }\end{array}$ & $\begin{array}{l}\mathrm{PHC}(\mathrm{n}=5) \\
\text { No (\%) }\end{array}$ \\
\hline Waiting area has benches in covered/shaded areas & $3(100)$ & $5(100)$ \\
\hline Drinking water available for the clients & $3(100)$ & $5(100)$ \\
\hline $\begin{array}{l}\text { All occupied beds have mattresses, rubber cover \& } \\
\text { clean bed sheet }\end{array}$ & $3(100)$ & $3(60)$ \\
\hline Toilet facilities for women & $3(100)$ & $3(60)$ \\
\hline $\begin{array}{l}\text { A labour separate room/ delivery room with } \\
\text { separate curtains on door \& windows for privacy }\end{array}$ & $3(100)$ & $5(100)$ \\
\hline
\end{tabular}

Table No-5: Availability of Infection Prevention Supplies at CHC and PHC.

\begin{tabular}{|l|l|l|}
\hline \multicolumn{1}{|c|}{$\begin{array}{c}\text { Name of infection prevention } \\
\text { supplies }\end{array}$} & $\begin{array}{c}\text { CHC (N=3) No } \\
(\%)\end{array}$ & $\begin{array}{l}\text { PHC (N=5) No } \\
(\%)\end{array}$ \\
\hline Surgical \& utility gloves & $3(100)$ & $5(100)$ \\
\hline $\begin{array}{l}\text { Bleaching powder, plastic buckets, mugs, } \\
\text { soap \&mops }\end{array}$ & $3(100)$ & $5(100)$ \\
\hline Surgical attires & $3(100)$ & $5(100)$ \\
\hline
\end{tabular}

Table No-6: Distribution of Health care facilities on Immunization service delivery (CHC,PHC \& S/C).

\begin{tabular}{|l|l|l|l|}
\hline $\begin{array}{l}\text { Child health care activities immunization } \\
\text { service delivery }\end{array}$ & $\begin{array}{l}\mathrm{CHC}(\mathrm{n}= \\
\mathbf{3})(\%)\end{array}$ & $\begin{array}{r}\mathrm{PHC}(\mathrm{n} \\
\mathbf{5}) \\
(\%)\end{array}$ & $\begin{array}{l}\mathrm{S} / \mathrm{C}(\mathrm{n}= \\
\mathbf{1 0})(\%)\end{array}$ \\
\hline $\begin{array}{l}\text { Immunization session conducted as planned } \\
\text { of age }\end{array}$ & $3(100)$ & $5(100)$ & $10(100)$ \\
\hline $\begin{array}{l}\text { Sterile needle not touched by hand or swab } \\
\text { during the injection process }\end{array}$ & $3(100)$ & $5(100)$ & $10(100)$ \\
\hline $\begin{array}{l}\text { Needle cutter or puncture proof box used for } \\
\text { disposing syringes }\end{array}$ & $3(100)$ & $5(100)$ & $10(100)$ \\
\hline $\begin{array}{l}\text { Vaccine carrier kept closed during the } \\
\text { immunization sessions }\end{array}$ & $3(100)$ & $5(100)$ & $10(100)$ \\
\hline $\begin{array}{l}\text { Post immunization advice regarding side } \\
\text { effects and follow up visits }\end{array}$ & $2(66.66$ & $3(60)$ & $10(100)$ \\
\hline $\begin{array}{l}\text { Immunization card up dated or completed for } \\
\text { each child after administering the vaccines }\end{array}$ & $3(100)$ & $5(100)$ & $10(100)$ \\
\hline Vaccines logistics and supplies & $3(100)$ & $5(100)$ & $10(100)$ \\
\hline Cold chain management & $3(100)$ & $5(100)$ & $10(100)$ \\
\hline
\end{tabular}


\begin{tabular}{|l|l|l|l|}
\hline Anganwadi \& Asha participated in outreach sessions & - & - & $10(100)$ \\
\hline Drop-out cases were traced \& vaccine provided & $3(100)$ & $5(100)$ & $10(100)$ \\
\hline
\end{tabular}

Table No-7: Availability of Equipment and Supplies at CHC and PHC.

\begin{tabular}{|l|l|l|}
\hline Availability of equipments \& supplies & $\begin{array}{r}\text { CHC }(\mathbf{n}=\mathbf{3}) \mathbf{N o} \\
(\%)\end{array}$ & $\begin{array}{l}\text { PHC }(\mathbf{n}=\mathbf{5}) \text { No } \\
(\%)\end{array}$ \\
\hline BP apparatus \& stethoscope & $3(100)$ & $5(100)$ \\
\hline Adult \& infant weighing machine & $3(100)$ & $5(100)$ \\
\hline $\begin{array}{l}\text { Autoclave/boiler in working condition } \\
\text { (kerosene stove) }\end{array}$ & $2(66.66)$ & $3(60)$ \\
\hline Complete delivery kits/DDK & $3(100)$ & $5(100)$ \\
\hline Sterile MVA syringe & $2(66.66)$ & $0(0)$ \\
\hline Functional EVA available & $0(0)$ & $0(0)$ \\
\hline Paediatric resuscitation kits & $3(100)$ & $5(100)$ \\
\hline Suction apparatus & $3(100)$ & $3(60)$ \\
\hline Sufficient No.s of syringes \& needles & $3(100)$ & $5(100)$ \\
\hline Oxygen cylinder with tubing wrench\& & $3(100)$ & $2(40)$ \\
\hline disposable masks & & $5(100)$ \\
\hline Sterile suturing tray & $3(100)$ & \\
\hline
\end{tabular}

Table No-8: Distribution of client satisfaction on Child health care services at Primary Health

\section{Centre}

\begin{tabular}{|l|l|l|l|l|l|l|}
\hline Category & $\begin{array}{c}\text { Scores (12 } \\
\text { points scale) }\end{array}$ & ARI & Diarrhoea & Immunization & Others & Total \\
\hline Very good & $10-12$ & 3 & 1 & 6 & 5 & 15 \\
\hline Good & $7-9$ & 8 & 12 & 12 & 4 & 36 \\
\hline Average & $4-6$ & - & 7 & - & - & 07 \\
\hline Poor & $1-3$ & - & - & 2 & - & 02 \\
\hline Total & & 11 & 20 & 20 & 09 & 60 \\
\hline
\end{tabular}

\section{Discussion}

The role of health manpower in determining the quality of health care is now increasingly appreciated. There were only $66.66 \%$ availability of Obstetrics \& gynaecology specialist and paediatrician. Physician were available in $33.33 \%$ of CHCs. According to Facility Survey (2003), reported that the specialist Obs/gynaecologist (51\%) and paediatrician (54\%) were available at $\mathrm{CHCs}$ in India.

The staff nurse (83\%), pharmacists (81\%) and laboratory technicians $(87 \%)$ were available at $\mathrm{CHCs}$ in India. The National Commission on Macroeconomics and Health Survey (2005) showed that in CHCs alone, there is a shortfall of $62 \%$ sanctioned posts of specialists and of the remaining $38 \%$ are lying vacant.

Kapilashrami MC observed [6] that doctors, if posted doctor prefer to sit in their private clinics even during working hours.
Government has not been able to ensure that doctors and nurses where posted remain available at their headquarters for their service to the people. Satpathy S K (2005) [7], reported the vacancy position of four specialists in the $\mathrm{CHCs}$ range from $40-50 \%$ and that surgeons and O\&G specialists without an anaesthetist are not in position to deliver the required surgical interventions.

There is an acute shortage of anaesthetists in the country. In the present study showed that all the sub-centres had available health worker (F)/ANM. None of the S/Cs had the available health worker (M). According to Facility Survey (2003), reported $95.1 \%$ health worker $(F)$ in position and $67.7 \%$ health worker $(M)$ were available from no of health facility having sanctioned post.

Agarwal K.et al (1994) [8] reported that the ratios of various health care providers such as MOs, PHN, health visitors, ANMs to populations were not fulfilling the Government recommended ratios. So concluded that the health care providers therefore were unable to cater optimum services to the beneficiaries. In this study, all the health care facilities had proper arrangement for the segregation of wastes generated at the facilities.

This was probably due to implementation of Infection Management \& Environment Plan (IMEP) for Reproductive and Child health programme (phaseII) under Government of India Deptt.of Family Welfare, MOHFW,2004. By Ray SK [9] in his study in three districts of West Bengal also reported the general cleanliness of the facility at BPHC and Sub-centre were poor.

According to In CLEN study (2002-03) reported that waste segregation was being done only at $6.2 \%$ of health facilities at country level. Gupte M., Bandeswar S and Pisal H (1999) [10], reported in their studies that cleanliness is an important criterion for general health care and deliveries.

In the present study, it had been observed that all the health care facilities had waiting areas with benches in covered/ shaded areas and available drinking water facility for the clients. $75 \%$ of the health facilities had the beds with mattresses, rubber cover and sheets for the clients. Toilet facilities for women were available in all the $\mathrm{CHCs}$ and $60 \%$ of PHCs.

As goal of health system is customer satisfaction, which WHO refers to the health systems responsiveness. 
Health systems have to be responsiveness to the needs of the customer satisfaction and the community [11]. Ray SK (2004-05) reported in his study that inadequate waiting space and unusable toilets at BPHC and S/C level in three districts in West Bengal.

Agarwal M et al (2001) in their study reported that the facility of separate room for consultation was totally absent in rural areas and at health posts. According to Facility Survey (2003), reported that $31 \%$ had separate LR, 55\% had separate toilet with running water, $56.1 \%$ had drinking water facility at $\mathrm{CHC}$ level.

At FRUs, 53.3\% separate aseptic L.R, 62.6\% separate toilet with running water and $50.9 \%$ of water facility. In the present study at PHCs level only $60 \%$ facilities had bed with mattresses, rubber cover and sheets for the clients. At all India level (2003, facility survey), reported $48.4 \%$ having $L R$, $66.5 \%$ water supply, $52.3 \%$ toilet facility and $71.3 \%$ had at least one bed at PHCs.

In Assam, 85.02\% having water supply, 56.21\% LR facility, $37.59 \%$ and $41.70 \%$ having at least one bed at PHCs (Facility Survey, 2003). The toilet facility and curtain on windows to ensure privacy for the clients comfort had been observed in $70 \%$ of the Sub-centres in this study. None of the S/Cs had the electricity facility with backup.

The sitting arrangements and drinking water facilities were available in all the S/Cs. By facility survey 2003 , reported $78.8 \%$ having drinking water facility, $73.6 \%$ toilet facility, $43.1 \%$ had electricity facility at $S / C s$ level. In the present study, the infection prevention supplies at $\mathrm{CHCs}$ and $\mathrm{PHCs}$ were available. Sharma $P$ et al [18] also in their study reported non-availability of disposable gloves and antiseptic solutions at the health facilities.

In the present study, it had been observed that all the CHCs and PHCs had well maintained the immunization service delivery. The post immunization advice regarding side effects and follow up were observed in only $66.66 \%$ of $\mathrm{CHCs}$ and $60 \%$ of PHCs. The vaccines logistics and supplies were available in all the health care facilities.

Agarwal M et al, 2004 reported only $30 \%$ of clients were advised about importance of completing vaccination schedule in comparison to $73,3 \%$ among urban clients, only $2 / 3$ rd clients were reminded about the next visit.
Similar findings reported by Gulati et al17, that a greater proportion of mothers of rural area as compared to that of urban areas were ignorant about the benefits of immunization.

Aswar et al [12] also reported mothers were not knowing the importance of immunization and immunization schedule. Perrey $\mathrm{H}$ [13] et al 1998 in their study for assessment of quality of immunization service found that the knowledge of immunization schedule of health worker was good. Steer land PH et al (1999) 12 in their study found that immunization cards were absent in many of the centres in Bangladesh.

Availability of an immunization document is the best proof of the child being immunized K Suresh (2000) [19]. Cutts F T et al 1990, [15] in their study observed that only half of the clients whose children were vaccinated were informed about the vaccine reactions or about the name of the vaccine received. Full course of potent vaccines given at right age and at right interval, by right technique with a valid documentation constitutes the quality criteria for vaccination services (Tapare VS, Borle PS 2006) [16].

At the S/cs, the immunization service delivery also found to be satisfactory. The advice on immunization and follow up visits as well as updated immunization card was also found to be $100 \%$ at all the S/cs. The drop out rates were also traced by the ANM. Anganwadi workers and ASHA also were found to be participated during the immunization sessions at all the Sub-centres. In the present study, the availability of equipments and supplies such as BP apparatus and stethoscope, infant and adult weighing machine were available in all the $\mathrm{CHCs}$ and PHCs.

The autoclave/ boiler were available in $66.66 \%$ of $\mathrm{CHCs}$ and $60 \%$ of PHCs. The complete delivery kits were available in all the CHCs and PHCs. The sterile MVA syringes were available in $66.66 \%$ of $\mathrm{CHCs}$ and none of the PHCs. The functional EVA syringes were not available in the health care facilities. The paediatric resuscitation kits were available in all the health care facilities. The suction apparatus were available in all the $\mathrm{CHCs}$ and $60 \%$ of the PHCs.

The oxygen cylinder with tubing wrench, disposable masks were available in all the $\mathrm{CHCs}$ and only $40 \%$ of PHCs. In the present study, it had been observed that $90 \%$ of S/Cs had BP apparatus and stethoscope and $100 \%$ of weighing machine were available at S/Cs. 
None of the S/C $\mathrm{s}$ had the available supply of paediatric resuscitation kit, labour table, step stool. In a study conducted by Agarwal M et al in 2001, stated that only $66.66 \%$ had stethoscope and BP instruments, weighing machine available at S/cs.

By facility survey 2003, reported $86.7 \%$ \& $84.9 \%$ had infant \& adult weighing machine, $65.9 \%$ BP apparatus, $79.5 \%$ stethoscope available at S/Cs in India. Steefland et al (1999) 14 in a multicounty study for assessment of EPI services found shortages of needles in two out of seven centres and syringes in four out of seven centres in Phillipines. The assessment of client satisfaction is inevitably subjective, because of educational, social, economic and linguistic differences between health professional and their clients.

The perception of quality varies from person to person according to individual's knowledge, values and resources (Humberto de Novaes, 1993). In this study, most of the patients were satisfied with child health care services at the health care facilities. By B S Akoijam et al (2007) [21] reported that most of the patients were satisfied with overall care received by the health care provider at the tertiary care hospital.

By Banerjee B (2003) [20] in their study found that the main deficiency regarding days and timing of the availability of specific services and the location of different service outlets within the centre by the clients.

\section{Conclusion}

The present study concluded that the quality of child health services were average at CHCs, PHCs and $\mathrm{S} / \mathrm{C}$ level. The child health care activities that observed at the CHCs and PHCs in areas of immunization services and cold chain maintenance was found to be satisfactory.

Recommendation: Based on the studies the following findings are recommended-

- The infrastructure gap of S/C,PHC,CHC should be met.

- Available untrained manpower should be trained and vacancy should be filled-up.

- There must be periodical orientation of medical as well as paramedical staffs at the health care facilities.

\section{Reference}

01. Gopalon C, Kaur H. Child care in India Emerging Challenges; Towards Better Nutrition, Problems \& Policies, Nutrition Foundation of India. special publication services 9, New Delhi. 110.

[Crossref]

02. Park K. Textbook of Preventive and Social Medicine. 22nd Ed. 2009.

[Crossref]

03. Quality Assurance for District Reproductive and Child health services in Public Health System; An operational manual. Governtment of India.

[Crossref]

04. Al-Assaf AF, C Q A. Health Care Quality, International Perspective, World Health Organization, Regional Office for South-East Asia.

[Crossref]

05. Donabedian A. Exploration in quality assessment \& monitoring, The definition of quality \& approaches to its assessment. Ann Arbor MI Health Administration Press. 1;1980.

[Crossref]

06. Kapilashrami MC. Universal access to health-a rights based approach. Indian J Public Health. 2005;49(2)48-52.

[Crossref]

07. Satpathy SK. Public health infrastructure in rural India- challenges and opportunities. Indian J Public Health. 2005;49(2)57-62.

[Crossref]

08. Agarwal M, et al. Quality of reproductive health care at primary level. IJCM. 2001;26(3)119-27. [Crossref]

09. Ray SK, Basu SS, Basu AK. An assessment of rural health care delivery system in some areas of West Bengal-an overview. Indian J Public Health. 2011;55(2)70-80. doi: 10.4103/0019-557X.85235 [Crossref]

10. Gupte $M$, et al. Improving Quality of Care in India's Family Welfare. Programme the challenge ahead. 1999.

[Crossref]

11. Agarwal D. Health Sector Reforms- Relevance in India. IJCM. 4;2006.

[Crossref] 
12. Aswar NR, Deotale PG, Kale KM, Bhawalkar JS, Dhage VR. Sociomedical correlates of missed opportunities for immunisation. Indian J Public Health. $1999 ; 43(4) 148-51$.

[Crossref]

13. Perry $H$, David $S$, et al. Impact of a community based comprehensive Primary Health care programme on Infant and Child mortality in Bolivia. J Health Population Nutrition. 2003;21(4); 383-395.

[Crossref]

14. Streefland $\mathrm{PH}$, et al. Quality of Vaccination services \& Social demands for Vaccination in Africa or Asia. Bulletin of World Health Organization. 1999;77(9)722-30.

[Crossref]

15. Cutts $F$, et al. Application of multiple methods to study the immunization programme in an Urban area of Guinea. Bulletin of the World Health Organization. 1990;68(6)769-776.

[Crossref]

16. Tapare VS, Borle PS. Assessment of vaccination performance by Lot Quality technique in an Urban community of Miraj. IJCM. 2017;31(3)181-182.

[Crossref]
17. Gulati N, et al. Factors Influencing Immunization, Status of Urban \& Rural ChildrenIn New Delhi. IJCM. 1990;15(4)180-184. [Crossref]

18. Sharma P, et al. Structural Quality of Subcentres in Wardha District, Maharastra.

[Crossref]

19. Suresh K, Saxena D. Trends and Determinants of Immunization Coverage in India. Journal of Indian Medical Association. 2000;98(1)10-14. [Crossref]

20. Banerjee B. Qualitative Analysis of Maternal \& Child health services of an Urban health care centre by assessing client perception in terms of awareness satisfaction \& service utilization. IJCM. 2003;28(4).

[Crossref]

21. Akoijam BS, Konjengbam S, Bishwalata R, Singh TA. Patients' satisfaction with hospital care in a referral institute in Manipur. Indian J Public Health. 2007;51(4)240-3.

[Crossref] 